\title{
ФОРМИРОВАНИЕ МЕТОДОЛОГИЧЕСКОГО ПОДХОДА ИССЛЕДОВАНИЯ ПОВЕРХНОСТНО-АКТИВНЫХ ВЕЩЕСТВ ДЛЯ УВЕЛИЧЕНИЯ НЕФТЕОТДАЧИ ПЛАСТОВ (НА ПРИМЕРЕ МЕСТОРОЖДЕНИЯ УДМУРТСКОЙ РЕСПУБЛИКИ)
}

\author{
Наговицына Наталья Петровна 1 , \\ 19nagov97@mail.ru
}

\author{
Дерендяев Роман Алексеевич², \\ omgvood19@gmail.com \\ 1 ЗАО «Ижевский нефтяной научный центр», \\ Россия, 426057, г. Ижевск, ул. Свободы, 175. \\ 2000 «ЛУКОЙЛ-ПЕРМЬ», \\ Россия, 614990, г. Пермь, ул. Ленина, 62.
}

\begin{abstract}
Актуальность работы. В настоящее время большинство нефртяных месторождений России вступили в позднюю стадию разработки. В связи с истощением запасов легкоизвлекаемой нефти все большие усилия направляются на создание технологий и способов разработки, которые позволяют добывать углеводороды в осложненных условиях. Для дальнейшей разработки месторождений с трудноизвлекаемыми запасами требуется внедрение новых методов увеличения нефтеотдачи и применение новых реагентов. Значительная роль в данном вопросе отводится химическим методам, в частности применению растворов поверхностно-активных веществ. Воздействие водных растворов поверхностно-активных веществ улучшает реологические и фильтрационные характеристики нефти посредством снижения межфразного натяжения и повышения смачивающей способности. В связи с вышеизложенным актуальным представляется задача выбора поверхностно-активных веществ для применения в системе заводнения пластов, а также разработка методологических подходов по их подбору.

Цель: формирование методологического подхода исследования поверхностно-активных веществ, применяемых в системе заводнения, для увеличения нефтеотдачи пластов.

Объект: карбонатные коллектора месторождений Удмуртской Республики.

Методы: лабораторные исследования составов в свободном объеме, прибор для определения поверхностного натяжения растворов поверхностно-активных веществ - сталагмометр «Рубин-02 А» (ГОСТ Р 50097-92), фрильтрационные исследования на единичных образцах керна с моделированием пластовых условий на установках УИК-5ВГ и AFS-300 (OCT 39-204-86 и 39195-86), чентрифоугирование (ГОСТ 16887-71).

Результаты. Обозначена актуальная проблема - процесс подбора технологии поверхностно-активных веществ для эфрфективного применения в системе заводнения с целью достижения наибольшей нефртеотдачи пластов. Проанализированы поверхностно-активные вещества, нашедшие активное промьшленное применение на месторождениях России и за ее пределами. Проведена оценка физико-химических и технологических свойств поверхностно-активных веществ российского производства в соответствии с паспортными характеристиками, требованиями Положений предприятия-недропользователя и определена пригодность химических реагентов к дальнейшему применению. Рассмотрены методика и результаты определения коэффициента вытеснения нефти водным раствором поверхностно-активных веществ на образцах керна, отобранных с месторождений Удмуртской Республики. Предложен экспресс-метод оценки нефттевытесняющей способности поверхностно-активных веществ, являющийся более экономичным и энергоресурсным по сравнению со стандартными фрильтрационными исследованиями. По результатам проведения фильтрационных испытаний на керне установлено, что предлагаемый метод сопоставим с проведенными исследованиями. В иелом предложенная методология выбора состава поверхностноактивных веществ возможна для внедрения в локальные нормативные документы предприятия-недропользователя и использования с иелью подбора необходимого реагента для увеличения нефтеизвлечения.
\end{abstract}

\section{Ключевые слова:}

Увеличение нефтеотдачи, поверхностно-активные вещества, коэфрфициент извлечения нефтти, нефтеотмывающая способность, физико-химические свойства поверхностно-активных веществ, межфазное натяжение, вытесняющие свойства, вытеснение нефти, карбонатный коллектор, критическая концентрация мицеллообразования.

\section{Введение}

В настоящее время более половины месторождений Удмуртской Республики характеризуются ниспадающим трендом добываемой нефти, максимальные уровни добычи которых уже пройдены, основная доля остаточных запасов относится к трудноизвлекаемым (рис. 1). С целью снижения темпа падения добычи нефти данных месторождений и сохранения ее на максимально возможном уровне необходимо применение различных реагентов, внедрение методов для увеличения нефтеотдачи [1-12].
Выделяют следующие методы повышения нефтеотдачи пластов (ПНП) для увеличения коэффициента извлечения нефти (КИН) [13-18]:

- газовые (вытеснение нефти газом высокого давления и обогащенным газом, водогазовое воздействие);

- тепловые (вытеснение нефти теплоносителем, внутрипластовый очаг горения);

- физические (волновое, электромагнитное воздействие);

- химические (закачка ПАВ, полимерное, щелочное заводнение). 


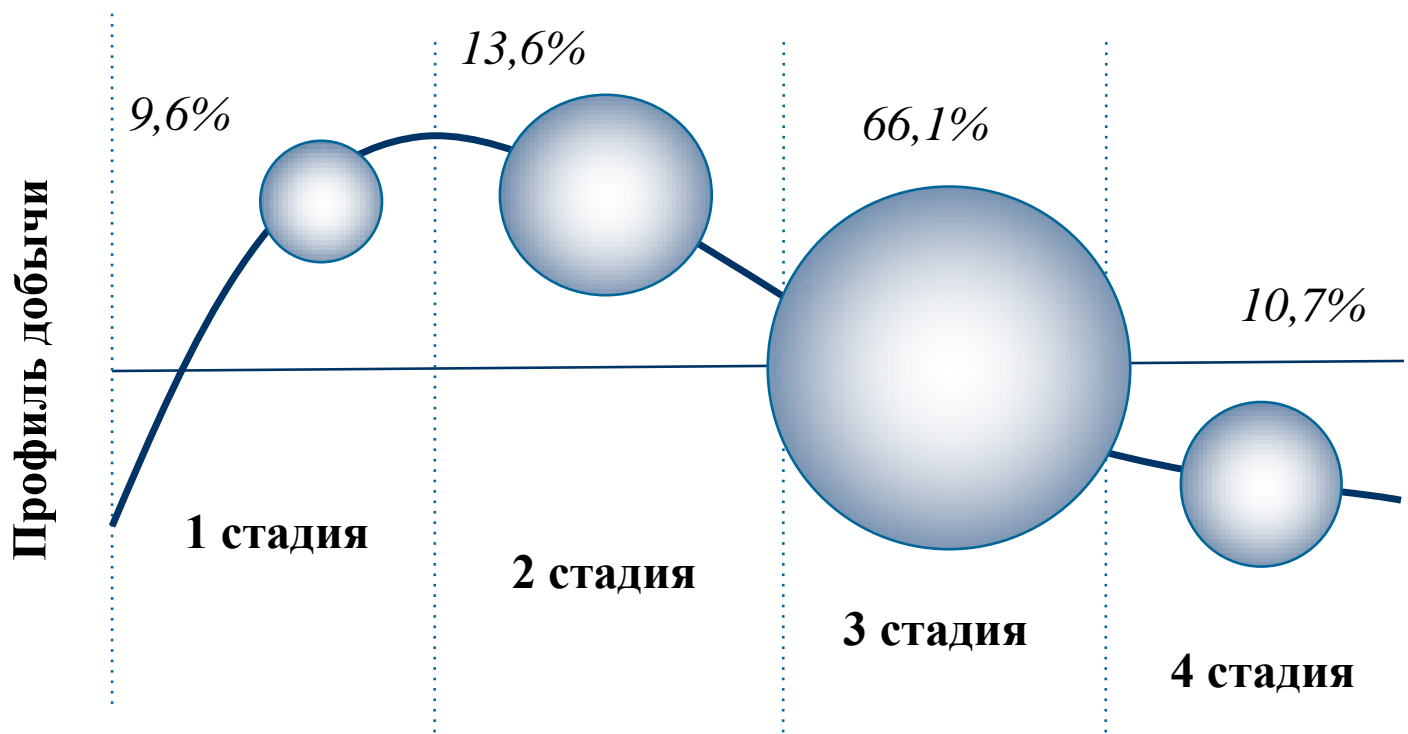

Pис. 1. Состояние разработки нефтяных месторождений в Удмуртской Республике

Fig. 1. Development status of the oil fields in the Udmurt Republic

Одним из методов повышения нефтеотдачи пластов, способствующих снижению межфазного натяжения, увеличению эффективной проницаемости по нефти, отмыву пленочной нефти, гидрофилизации поверхности горной породы являются технологии с применением поверхностно-активных веществ (ПАВ).

Применение ПАВ как перспективного реагента для ПНП стало возможным после опубликования результатов экспериментальных и промысловых испытаний в США в 40-х гг. XX в. по использованию данных добавок при заводнении нефтяных пластов. Неопровержимым достоинством их внедрения является сохранение фильтрационных свойств продуктивных коллекторов и отсутствие негативного влияния на процессы транспортировки и подготовки нефти [13, 18-21]. В Российской Федерации большой объем внедрения технологий с применением ПАВ различной концентрации осуществлен на месторождениях Башкортостана, Татарстана и Западной Сибири. Так, например, на Ромашкинском месторождении за счет внедрения водо- и маслорастворимых ПАВ добыто 2,9 млн т нефти. Эффективной оказалась также закачка водорастворимых ПАВ для первичного вытеснения нефти на терригенном коллекторе Ромашкинского месторождения - в среднем около 60 т дополнительно добытой нефти на одну тонну реагента [22]. Известен опыт применения анионных ПАВ в составе ASP-технологии (химическое заводнение пласта трехкомпонентной смесью) на истощенном участке Западно-Салымского месторождения в ХантыМансийском автономном округе-Югре. В результате на опытном участке месторождения удалось достичь коэффициента извлекаемой нефти в 69 \%, из них эффект от применения ASP-заводнения - 17 \% [23]. Таким образом, задача исследования ПАВ как технологии для повышения нефтеотдачи пластов представляется актуальной, потому как рост КИН хотя бы на несколько десятых долей процента позволит суще- ственно нарастить объемы дополнительно добываемой нефти.

К основным факторам, влияющим на успешность применения какого-либо раствора ПАВ, можно отнести геологическое строение продуктивных пластов, геологофизические характеристики пород-коллекторов, текущее и энергетическое состояние объекта разработки, а также опыт использования конкретной технологии. Также необходимо принять во внимание, что правильный выбор технологии с учетом индивидуальных особенностей пласта, а также воздействие в необходимый момент времени приводят к существенному росту успешности реализации методов увеличения нефтеотдачи (МУН) и повышению эффективности разработки месторождения [8-11, 19-24].

Эффективность использования ПАВ в качестве повышения нефтеотдачи может быть существенно увеличена путем понимания соответствующего подхода по их подбору. Таким образом, данная работа посвящена формированию методологического подхода исследования ПАВ с целью повышения нефтеизвлечения для пластов месторождений Удмуртской Республики.

Для проведения исследований были выбраны составы: Неонол АФ 9-6, Atren SA-1, Биксол, Сульфен35, ОП-10. Подбор данных видов ПАВ производился исходя из опыта проведения мероприятий на месторождениях Удмуртской Республики, а также был учтен отечественный и зарубежный опыт использования ПАВ как метода увеличения нефтеотдачи [2, 13-15, 18, 19, 22-29].

Свойства составов были исследованы и проанализированы в зависимости от их областей применения по отношению к карбонатным коллекторам месторождения А (верейско-башкирский объект). Выбор данного месторождения обусловлен тем, что данный объект вступил в позднюю стадию разработки, а также характеризуется образованием многочисленных 
застойных зон, тупиков, слабо вырабатываемых участков и слоев с отличающимися по объемам значениями остаточных запасов нефти и промытых зон. Основные геолого-физические характеристики исследуемого объекта представлены в табл. 1.

Таблица 1. Геолого-физическая характеристика исследуемого объекта

Table 1. Geological and physical characteristics of the studied object

\begin{tabular}{|c|c|}
\hline Параметр/Parameter & $\begin{array}{c}\text { Месторождение } \mathrm{A} \\
\text { (верейско-башкирский } \\
\text { объект) } \\
\text { Field A (object } \mathrm{C}_{2} \mathrm{vr}-\mathrm{C}_{2} \mathrm{~b} \text { ) }\end{array}$ \\
\hline $\begin{array}{l}\text { Средняя глубина залегания, м } \\
\text { Average depth, m }\end{array}$ & -1043 \\
\hline $\begin{array}{l}\text { Пористость, \% } \\
\text { Porosity, } \%\end{array}$ & 16,0 \\
\hline $\begin{array}{l}\text { Проницаемость, мД } \\
\text { Permeability, mD }\end{array}$ & 121 \\
\hline $\begin{array}{l}\text { Средняя эффективная нефтенасы- } \\
\text { щенная толщина, м } \\
\text { Average effective net weight, m }\end{array}$ & 7,9 \\
\hline $\begin{array}{l}\text { Коэффициент песчанистости, д.ед. } \\
\text { Sandiness coefficient, the share of units }\end{array}$ & 0,39 \\
\hline $\begin{array}{l}\text { Коэффициент расчлененности, д. ед. } \\
\text { Dismemberment coefficient, the share } \\
\text { of units }\end{array}$ & 10,33 \\
\hline $\begin{array}{l}\text { Вязкость нефти в пластовых услови- } \\
\text { ях, мПа·с } \\
\text { Oil viscosity at reservoir conditions, } \\
\mathrm{MPa} \cdot \mathrm{s}\end{array}$ & 33,5 \\
\hline $\begin{array}{l}\text { Минерализация воды, г/л } \\
\text { Water mineralisation, g/l }\end{array}$ & 249,7 \\
\hline $\begin{array}{l}\text { Газосодержание, } \mathrm{m}^{3} / \mathrm{T} \\
\text { Gas content, } \mathrm{m}^{3} / \mathrm{t}\end{array}$ & 11,3 \\
\hline $\begin{array}{l}\text { Начальное пластовое давление, МПа } \\
\text { Initial reservoir pressure, MPa }\end{array}$ & 11,9 \\
\hline $\begin{array}{l}\text { Начальная пластовая температура, }{ }^{\circ} \mathrm{C} \\
\text { Initial reservoir temperature, }{ }^{\circ} \mathrm{C}\end{array}$ & 25,7 \\
\hline
\end{tabular}

Лабораторные исследования водных растворов ПАВ

Методология подбора ПАВ состояла из следующих этапов:

- изучение российского и зарубежного опыта применения ПАВ для увеличения нефтеотдачи;

- оценка физико-химических и технологических свойств ПАВ в соответствии с требованиями Положений предприятия-недропользователя;

- оценка нефтевытесняющей способности ПАВ стандартизируемым методом согласно ОСТ 39-195-86 на фильтрационной установке и экспресс-методом;

- расчет технологических и экономических показателей проекта.

Проведен комплекс исследований в свободном объеме, включающий в себя оценку внешнего вида состава ПАВ; определение физико-химических свойств реагентов (плотности, температуры застывания, массовую долю активного вещества); определение стабильности ПАВ при воздействии с пластовыми флюидами (вода и нефть обозначенных объектов); определение технологических свойств составов в условиях проведения работ (коррозионная агрессивность раствора ПАВ). Результаты исследований представлены в табл. 2.
Таблииа 2. Физико-химические и технологические свойства исследуемых ПАВ

Table 2. Physico-chemical and technological properties of the studied surface-active substances

\begin{tabular}{|c|c|c|c|c|c|}
\hline $\begin{array}{l}\text { Параметр } \\
\text { Parameter }\end{array}$ & 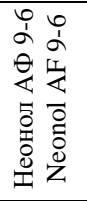 & 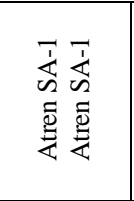 & 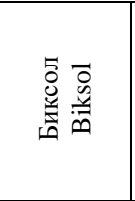 & 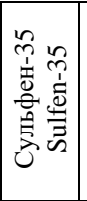 & $\begin{array}{l}0 \\
\frac{0}{1} \\
\frac{1}{0}\end{array}$ \\
\hline $\begin{array}{l}\text { Внешний вид } \\
\text { Physical form }\end{array}$ & \multicolumn{5}{|c|}{$\begin{array}{c}\text { однородная не расслаивающаяся на фазы } \\
\text { бесцветная жидкость, без взвешенных и } \\
\text { оседающих частиц } \\
\text { homogeneous, colorless liquid, not } \\
\text { delaminating into phases, without suspended } \\
\text { and settling particles }\end{array}$} \\
\hline $\begin{array}{l}\text { Температура засты- } \\
\text { вания, }{ }^{\circ} \mathrm{C} \\
\text { Freezing point, }{ }^{\circ} \mathrm{C}\end{array}$ & -15 & $\begin{array}{c}\text { менее }-50 \\
\text { less-50 }\end{array}$ & $\begin{array}{c}\text { менее }-50 \\
\text { less }-50\end{array}$ & -25 & -15 \\
\hline 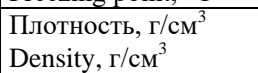 & 1,045 & 0,957 & 1,008 & 1,048 & 1,089 \\
\hline $\begin{array}{l}\text { Массовая доля } \\
\text { активного веще- } \\
\text { ства, \% } \\
\text { Mass fraction of } \\
\text { active substance, \% }\end{array}$ & 93,06 & 32,89 & 32,34 & 10,71 & 10,20 \\
\hline 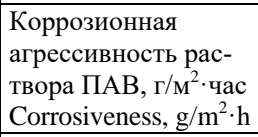 & 0,032 & 0,025 & 0,015 & 0,028 & 0,018 \\
\hline $\begin{array}{l}\text { Совместимость } \\
\text { раствора ПАВ с } \\
\text { нефтью } \\
\text { Compatibility of } \\
\text { surfactant solution } \\
\text { with oil }\end{array}$ & \multicolumn{5}{|c|}{ совместимо/compatible } \\
\hline $\begin{array}{l}\text { Совместимость } \\
\text { раствора ПАВ с } \\
\text { пластовой водой } \\
\text { Surfactant solution } \\
\text { compatibility with } \\
\text { formation water }\end{array}$ & $\begin{array}{l}\text { нали- } \\
\text { чие } \\
\text { геля } \\
\text { gel }\end{array}$ & \multicolumn{4}{|c|}{ совместимо/compatible } \\
\hline
\end{tabular}

Процесс исследования совместимости ПАВ с пластовой водой заключался в следующем. Для испытания готовили 0,$1 ; 0,5 ; 1,0 ; 2,0$ \% растворы ПАВ в минерализованной пластовой воде месторождения А. Выдержка растворов ПАВ после приготовления производилась в течение 24 часов. Изготовленный состав удовлетворяет условиям, если после взаимодействия с пластовой водой не происходит выпадения осадка и расслоения. На основании проведенных исследований отмечается образование прозрачного раствора со всеми исследуемыми ПАВ кроме Неонол АФ 9-6, где наблюдается наличие геля. Процесс исследования совместимости нефти и ПАВ заключался в приготовлении растворов ПАВ аналогичной концентрации и выдерживании их в течение суток после перемешивания с нефтью. По результатам исследований все исследуемые составы признаны совместимыми, расслоений и осадков не выявлено.

Далее производилось вычисление межфазного натяжения растворов ПАВ на границе с нефтью. Определение поверхностного натяжения производилось с помощью специального прибора - сталагмометр «Рубин-02 А». Значения межфазного натяжения определялись согласно методу отрыва капели по ГОСТ Р 50097-92. Результаты исследований межфазного натяжения представлены на рис. 2. 


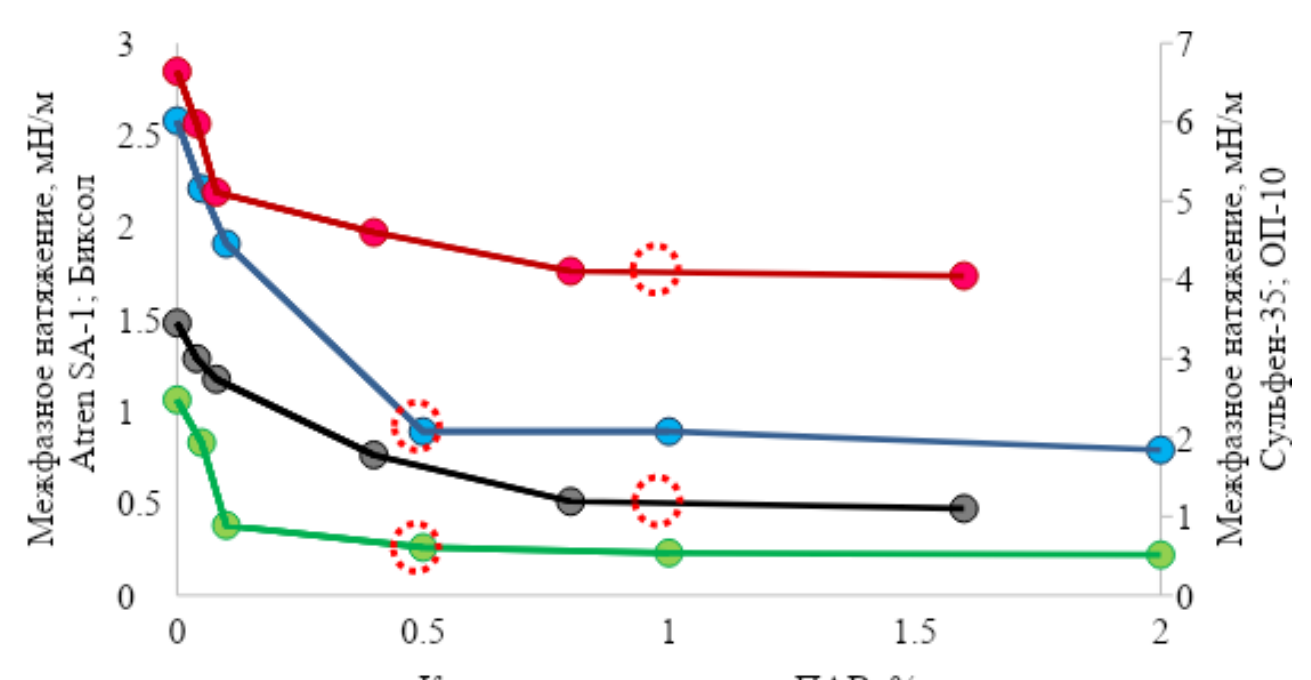

Концентрация раствора ПАВ ,\%

\section{Atren SA-1 •Биксол •Сульфен-35 ०П-10} Рис. 2. Зависимость межфазного натяжения от концентрации ПАВ в растворе. : - критическая концентрация
мицеллообразования

Fig. 2. Dependence of interfacial tension on concentration of surface-active substances. $\therefore-$ critical concentration for micelle formation

На основании анализа графиков зависимости межфазного натяжения от концентрации ПАВ установлено, что в растворах всех исследуемых ПАВ существует некоторая насыщенность, после достижения которой при добавлении в состав ПАВ плотность вещества на границе раздела фаз остается постоянной это критическая концентрация мицеллообразования (ККМ). Эта концентрация поверхностно-активных веществ является достаточной для достижения эффекта снижения межфазного натяжения на границе нефть/раствор ПАВ. По результатам исследований границы раздела фаз установлено, что растворы ПАВ в рабочих концентрациях обеспечивают снижение поверхностной энергии на границе с нефтью более чем на $30 \%$ по сравнению с силой натяжения без применения реагента.

Таблица 3. Результаты фильтрационных исследований ПАВ на карбонатном коллекторе

Table 3. Results of filtration studies of surfactants on carbonate reservoirs

\begin{tabular}{|c|c|c|c|c|}
\hline \multirow[b]{2}{*}{$\begin{array}{l}\text { ПAB } \\
\text { SAS }\end{array}$} & \multirow{2}{*}{ 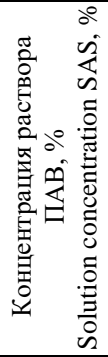 } & \multicolumn{3}{|c|}{$\begin{array}{c}\text { Коэффициент вытеснения нефти, д. ед. } \\
\text { Oil displacement coefficient, } \\
\text { decimal quantity }\end{array}$} \\
\hline & & $\begin{array}{c}\text { До обработ- } \\
\text { ки раствором } \\
\text { ПАВ } \\
\text { Before } \\
\text { treatment } \\
\text { with } \\
\text { surfactant } \\
\text { solution }\end{array}$ & \begin{tabular}{|c|} 
После обра- \\
ботки рас- \\
твором ПАВ \\
After \\
treatment \\
with a \\
surfactant \\
solution \\
\end{tabular} & $\begin{array}{c}\text { Относи- } \\
\text { тельное } \\
\text { увеличе- } \\
\text { ние, \% } \\
\text { Relative } \\
\text { increase, \% }\end{array}$ \\
\hline $\begin{array}{l}\text { Atren SA-1 } \\
\text { Atren SA-1 }\end{array}$ & 0,5 & 0,603 & 0,668 & 10,8 \\
\hline $\begin{array}{l}\text { Биксол } \\
\text { Biksol }\end{array}$ & 0,1 & 0,588 & 0,619 & 5,3 \\
\hline $\begin{array}{l}\text { Сульфен-35 } \\
\text { Sulfen-35 }\end{array}$ & 1,0 & 0,618 & 0,638 & 3,2 \\
\hline $\begin{array}{l}\text { OП-10 } \\
\text { OP-10 }\end{array}$ & 1,0 & 0,598 & 0,626 & 4,7 \\
\hline
\end{tabular}

С целью определения основных коллекторских свойств горных пород фильтрационные исследования образцов керна производились с учетом термобарических условий залегания данных пород на установках УИК-5ВГ и AFS-300. Полученные результаты проведенных испытаний представлены в табл. 3 .

При проведении фильтрационных испытаний использовались карбонатные образцы керна с эффективной проницаемостью по нефти в диапазоне от $63,4 \cdot 10^{-3}$ до $541,7 \cdot 10^{-3}$ мкм $^{2}$. Последовательность выполнения работ на фильтрационной установке тестируемых растворов следующий:

1) образец помещается в установку AFS-300, где производится моделирование пластовых условий;

2) насыщение образца моделью пластовой нефти путем её фильтрации через керн со скоростью 0,1 $\mathrm{cm}^{3} /$ мин в количестве не менее трех объемов пустотного пространства образца;

3) выдержка насыщенного образца керна при термобарических условиях пласта в течение не менее суток для стабилизации свойств системы флюидпорода;

4) определение фазовой проницаемости по нефти керновых образцов с остаточной водонасыщенностью в прямом направлении «пласт-скважина» при создании пластового давления;

5) закачка вытесняющего агента (пластовой воды с раствором ПАВ) с расходом $0,1 \mathrm{~cm}^{3} /$ мин в прямом направлении через нефтенасыщенный керновый образец с остаточной водонасыщенностью;

6) непрерывное нагнетание вытесняющего агента до полного обводнения выходящей жидкости (порядка 3-5 объемов порового пространства образца);

7) создание фильтрации вытесняющего раствора жидкости в количестве двух объемов пор при скорости не менее $1 \mathrm{~cm}^{3} /$ мин; 
8) измерение объема дегазированной нефти с помощью специальной мерной бюретки;

9) вычисление коэффициента вытеснения нефти ( $\beta$ ) агентом:

$$
\beta=\frac{V_{\mathrm{H}}}{V_{\text {н нач }}},
$$

где $\beta$ - коэффициент вытеснения нефти агентом; $V_{\text {н нач }}-$ первоначальный содержащийся в керне объем нефти: определяется как разность объемов пустот и остаточной воды, приведенных к пластовым условиям; $V_{\text {н }}$ объем нефти, вытесненной из составных керновых образцов в ходе проведения фильтрационных испытаний.

Также, ввиду длительности и дорогостоящей процедуры проведения фильтрационных испытаний, были проведены исследования экспресс-метода оценки эффективности нефтевытесняющей способности ПАВ Сущность испытаний заключается в следующем.

Нефтеотмывающая способность ПАВ определяется методом центрифугирования. Для этого предварительно в течение 24 ч при пластовой температуре и

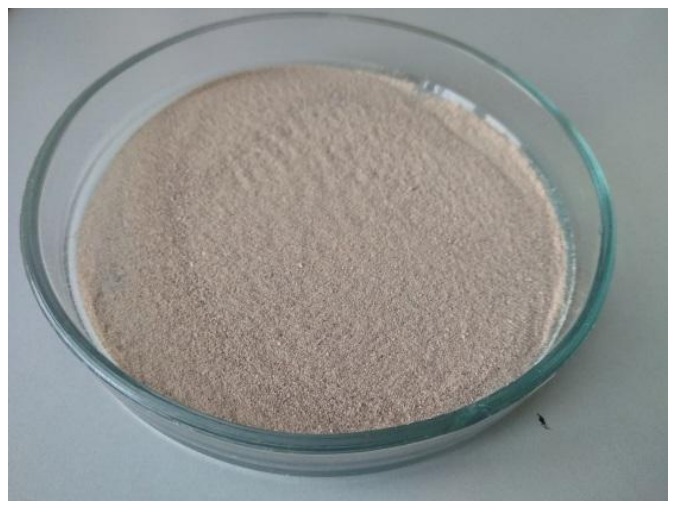

$a / a$

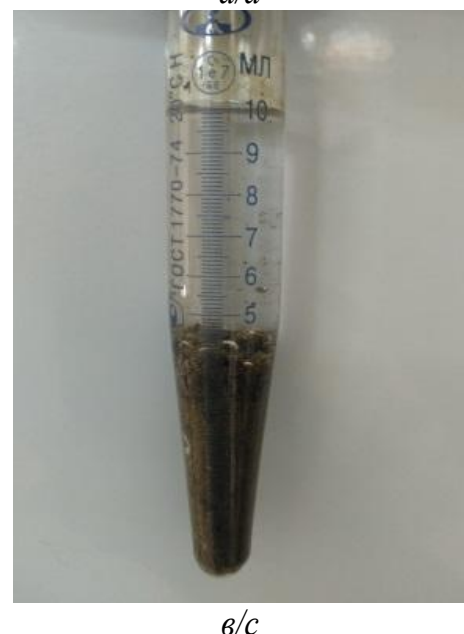

давлении произведено насыщение нефтью мраморной крошки, моделирующей состав карбонатного коллектора. По истечении суток контрольный объем (5 г) насыщенной нефтью мраморной крошки был помещен в проградуированную пробирку диаметром 10 мм (рис. 3). Далее производилось заполнение емкости раствором исследуемого ПАВ в объеме 6 мл. Центрифугирование проводится в три этапа по 15 мин с частотой вращения 1500 об/мин. После проведения опыта по градуированной шкале пробирки определяют объем нефти, вытесненной из образца.

В качестве объектов исследования выступили водные растворы с концентрацией ПАВ 0,$1 ; 0,5 ; 1,0 ; 2,0$ для определения эффективности действия экспрессметода, а также определения качественных и количественных различий в полученных результатах (рис. 4). На основе анализа полученных результатов исследований наибольшее вытеснение нефти водным раствором ПАВ при его минимальных затратах получено при концентрации, равной критической концентрации мицеллообразования (табл. 4).

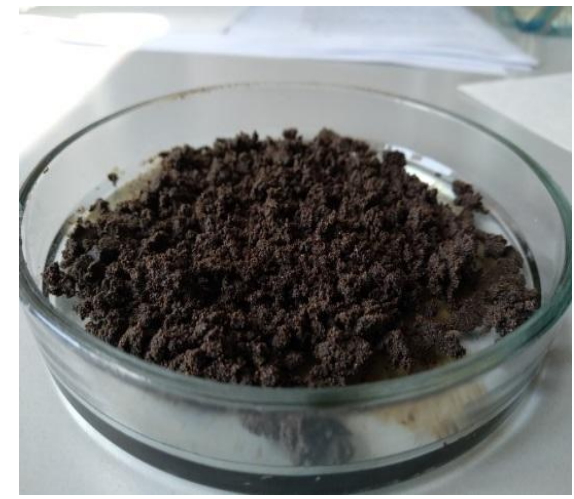

$6 / b$

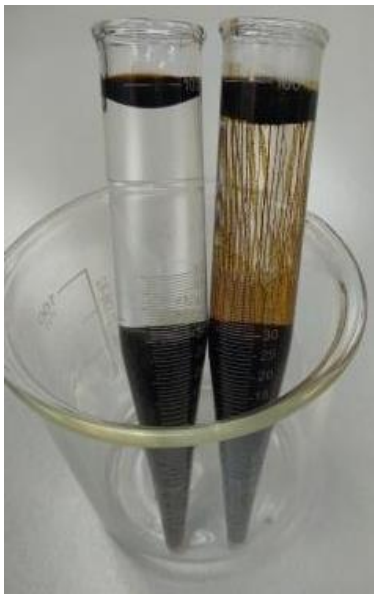

$2 / d$

Рис. 3. Последовательность проведения исследований на определение нефтеотмывающей способности ПАВ экспресс-методом: а) мраморная крошка - модель карбонатного типа коллектора; б) мраморная крошка, насыщенная нефтью; в) пробирка с нефтенасыщенной мраморной крошкой и раствором ПАВ; г) сравнение вытеснения нефти пластовой водой (слева) и водным раствором ПАВ (справа)

Fig. 3. Sequence of studies to determine the oil-washing ability of surfactants by the express method: a) marble chips - a model of the carbonate type of the reservoir; b) marble chips, saturated with oil; c) test tube with oil-saturated marble chips and a surfactant solution; d) comparison of oil displacement with formation water (left) and an aqueous surfactant solution (right) 


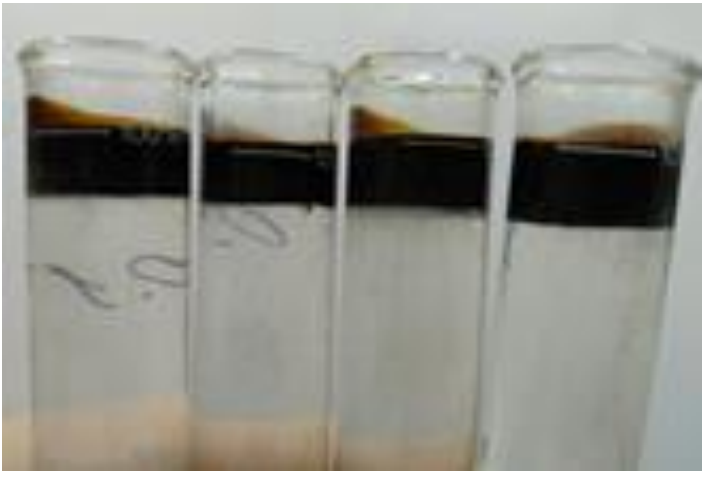

$a / a$

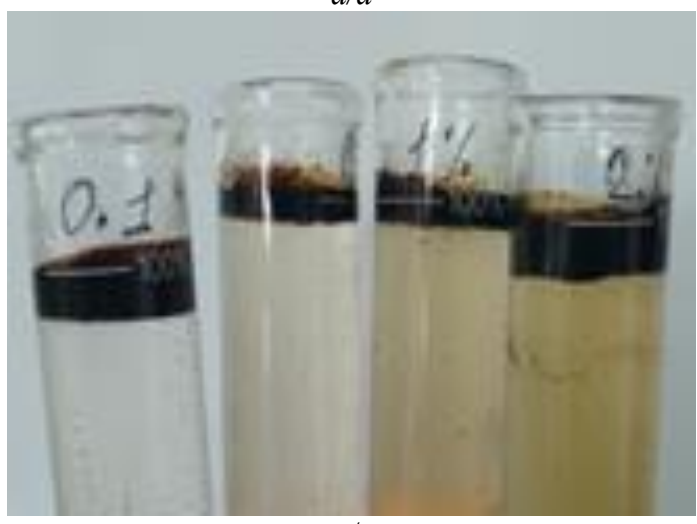

$B / C$

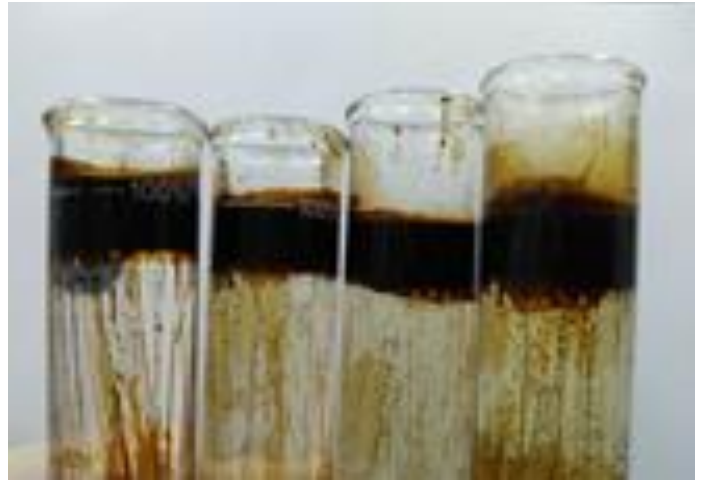

$\sigma / b$

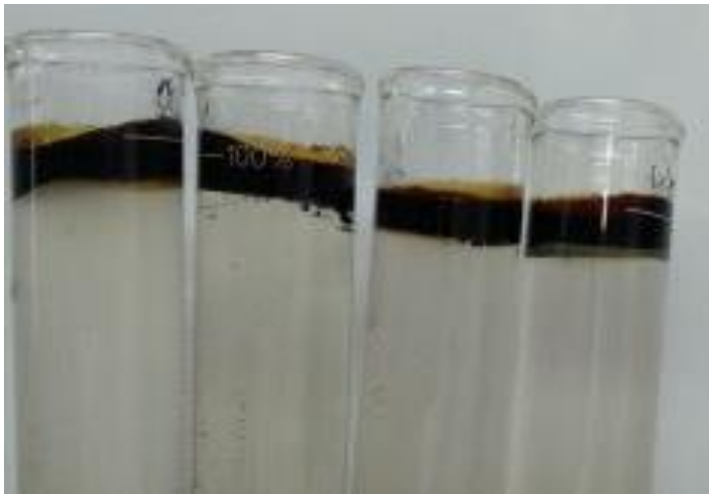

$2 / d$

Рис. 4. Результаты исследований оиенки нефтеотмывающей способности ПАВ экспресс-методом: a) Atren SA-1; б) Биксол; в) Сульфен-35; г) ОП-10

Fig. 4. Results of studies evaluating the oil washing ability of surfactants by express method: a) Atren SA-1; b) Biksol; c) Sulfen-35; d) OP-10

Таблица 4. Результаты исследований оценки нефтеотмывающей способности ПАВ экспрессметодом

Table 4. Results of studies evaluating the oil washing ability of surfactants by express method

\begin{tabular}{|c|c|c|}
\hline $\begin{array}{c}\text { Объект } \\
\text { исследова- } \\
\text { ния } \\
\text { Object of } \\
\text { research }\end{array}$ & $\begin{array}{c}\text { Концентра- } \\
\text { ция раствора } \\
\text { ПАВ, \% } \\
\text { Concentration } \\
\text { of SAS, \% }\end{array}$ & $\begin{array}{c}\text { Вытеснение нефти водным рас- } \\
\text { твором ПАВ относительно пла- } \\
\text { стовой воды, ед. } \\
\text { Oil displacement with an aqueous } \\
\text { surfactant solution relative to } \\
\text { produced water, unity }\end{array}$ \\
\hline $\begin{array}{l}\text { Пластовая } \\
\text { вода } \\
\text { Reservoir } \\
\text { water } \\
\end{array}$ & - & 1 \\
\hline \multirow{4}{*}{$\begin{array}{l}\text { Биксол } \\
\text { Biksol }\end{array}$} & 0,1 & 2,5 \\
\hline & 0,5 & 3 \\
\hline & 1 & 4 \\
\hline & 2 & 4,3 \\
\hline \multirow{4}{*}{$\begin{array}{l}\text { Atren SA-1 } \\
\text { Atren SA-1 }\end{array}$} & 0,1 & 2,5 \\
\hline & 0,5 & 3 \\
\hline & 1 & 3,3 \\
\hline & 2 & 4 \\
\hline \multirow{4}{*}{$\begin{array}{l}\text { Сульфен-35 } \\
\text { Sulfen-35 }\end{array}$} & 0,1 & 1,5 \\
\hline & 0,5 & 1,5 \\
\hline & 1 & 1,5 \\
\hline & 2 & 2,5 \\
\hline \multirow{4}{*}{$\begin{array}{l}\text { ОП-10 } \\
\text { ОР-10 }\end{array}$} & 0,1 & 1,5 \\
\hline & 0,5 & 1,5 \\
\hline & 1 & 2 \\
\hline & 2 & 2 \\
\hline
\end{tabular}

Таким образом, по результатам экспресс-метода оценки эффективности нефтевытесняющей способности ПАВ установлено, что растворы ПАВ в рабочих концентрациях увеличивают нефтевытеснение по сравнению с пластовой водой. На основании анализа результатов коэффициента вытеснения нефти, определенного экспресс-методом оценки и по фильтрационным испытаниям согласно ОСТ 39-195-86, выявлена соизмеримость данных значений, что подтверждает корреляционную зависимость определения коэффициента вытеснения нефти данными методами (рис. 5).

Также выполнено сравнение данных двух методов по определению коэффициента вытеснения путем суммирования затрат времени (ресурсов) производства работ. Оценка времени производилась по каждой отдельно взятой операции в необходимой последовательности выполнения работ (табл. 5).

Предлагаемый экспресс-метод оценки моющей способности ПАВ является менее трудозатратным процессом: в среднем экономия времени составляет 48 ч на одного человека. Таким образом, экспрессметод определения моющей способности ПАВ является более экономно-ресурсным, однако имеет более низкую точность, чем стандартные фильтрационные испытания по ОСТ 39-195-86, что подтверждается сопоставлением результатов исследований данных двух методов (рис. 5). 


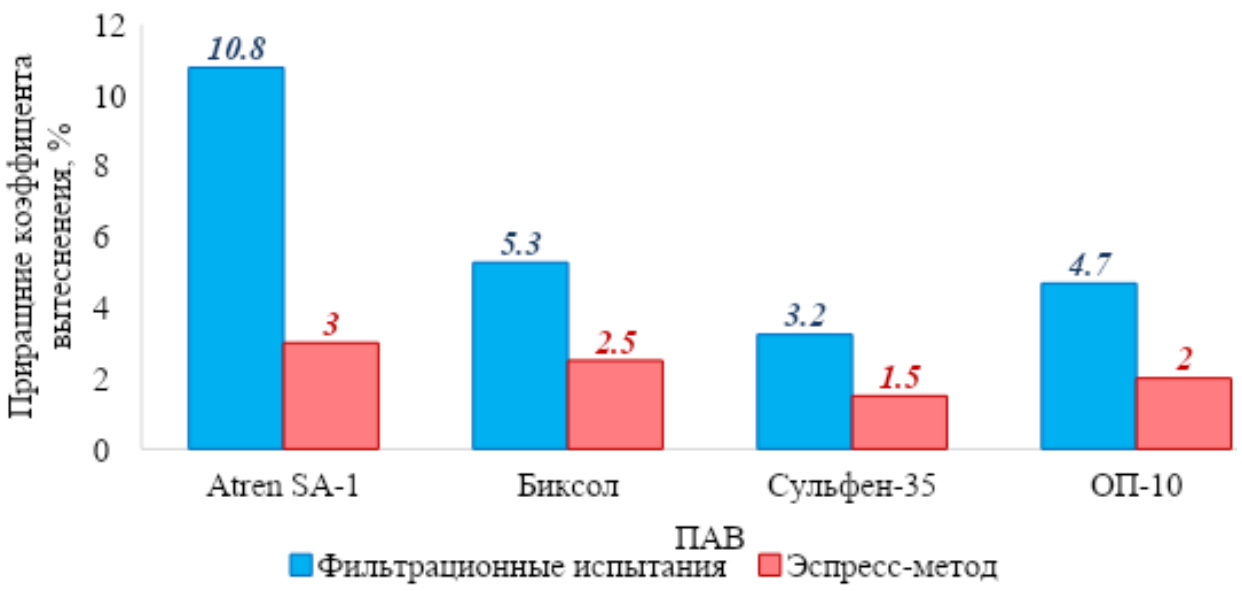

Рис. 5. Сопоставление результатов определения коэффициента вытеснения на фильтрационной установке и экспресс-метода

Fig. 5. Comparison of the results of determining the displacement coefficient in a filtration unit and the express method

Таблица 5. Сравнение трудозатрат методов определения коэффициента вытеснения

Table 5. Comparison of labor contribution of methods for determining the coefficient of displacement

\begin{tabular}{|c|c|c|c|}
\hline \multicolumn{2}{|c|}{$\begin{array}{c}\text { Фильтрационные испытания } \\
\text { по OCT 39-195-86 } \\
\text { Filtration tests }\end{array}$} & \multicolumn{2}{|c|}{$\begin{array}{l}\text { Экспресс-метод } \\
\text { Express method }\end{array}$} \\
\hline $\begin{array}{l}\text { Виды работ } \\
\text { Туре of work }\end{array}$ & \begin{tabular}{|c|} 
Трудоза- \\
траты, \\
чел·час \\
Labor \\
contributio \\
n, man- \\
hours
\end{tabular} & $\begin{array}{l}\text { Виды работ } \\
\text { Туре of work }\end{array}$ & $\begin{array}{l}\text { Трудоза- } \\
\text { траты, } \\
\text { чел·час } \\
\text { Labor } \\
\text { contributio } \\
\text { n, man- } \\
\text { hours }\end{array}$ \\
\hline $\begin{array}{l}\text { Отбор и подго- } \\
\text { товка образцов } \\
\text { Sampling and } \\
\text { preparation of rock } \\
\text { samples }\end{array}$ & 10,83 & \begin{tabular}{|l|} 
Приготовление рас- \\
твора ПАВ \\
Preparation of surface- \\
active substance \\
solution
\end{tabular} & 1,03 \\
\hline \begin{tabular}{l|} 
Подготовка мо- \\
дели пласта \\
Reservoir model \\
preparation
\end{tabular} & 8,20 & $\begin{array}{l}\text { Насыщение мрамор- } \\
\text { ной крошки нефтью } \\
\text { Saturation of marble } \\
\text { chips with oil }\end{array}$ & 2,55 \\
\hline $\begin{array}{l}\text { Подготовка жид- } \\
\text { костей для про- } \\
\text { ведения экспери- } \\
\text { мента } \\
\text { Preparation of } \\
\text { fluids for the } \\
\text { experiment }\end{array}$ & 6,00 & $\begin{array}{l}\text { Заполнение пробирки } \\
\text { мраморной крошкой и } \\
\text { пластовой водой с } \\
\text { ПАВ } \\
\text { Filling the test tube } \\
\text { with marble chips and } \\
\text { produced water with a } \\
\text { surfactant }\end{array}$ & 0,15 \\
\hline $\begin{array}{l}\text { Фильтрационный } \\
\text { эксперимент } \\
\text { Filtration } \\
\text { experiment } \\
\end{array}$ & 24,57 & $\begin{array}{l}\text { Процесс центрифуги- } \\
\text { рования } \\
\text { Centrifugation }\end{array}$ & 1,15 \\
\hline $\begin{array}{l}\text { Анализ результа- } \\
\text { тов, расчеты } \\
\text { Analysis of results, } \\
\text { calculations } \\
\end{array}$ & 6,00 & $\begin{array}{l}\text { Анализ результатов, } \\
\text { расчеты } \\
\text { Analysis of results, } \\
\text { calculations }\end{array}$ & 2,33 \\
\hline $\begin{array}{l}\text { Итоговые трудо- } \\
\text { затраты } \\
\text { Total labor }\end{array}$ & 55,60 & $\begin{array}{l}\text { Итоговые трудозатра- } \\
\text { ты } \\
\text { Total labor }\end{array}$ & 7,21 \\
\hline
\end{tabular}

Конечным результатом проведенных исследований стало определение наиболее эффективного состава ПАВ для вытеснения нефти, а также определение экономической эффективности от применения определенного ПАВ в системе заводнения с последующим проведением опытно-промышленных испытаний на верейско-башкирском горизонте месторождения А. Таким образом, предложенная методология выбора состава ПАВ возможна для внедрения в локальные нормативные документы предприятия-недропользователя и использования с целью подбора необходимого реагента для увеличения нефтеизвлечения.

\section{Заключение}

В работе обозначена актуальная проблема - процесс подбора технологии ПАВ для эффективного применения в системе заводнения с целью достижения наибольшей нефтеотдачи пластов. Проанализированы составы, нашедшие активное промышленное применение на месторождениях России и за ее пределами. Проведена оценка физико-химических и технологических свойств ПАВ российского производства в соответствии с требованиями Положений предприятия-недропользователя и определена пригодность химических реагентов к дальнейшему применению. По результатам проведенных исследований сформирован методологический подход подбора ПАВ, а также получены результаты определения коэффициента вытеснения нефти его водным раствором на образцах керна, отобранных с месторождения Удмуртской Республики. Определение коэффициента вытеснения является важной задачей, потому как он напрямую связан с нефтенасыщенностью пласта и играет важную роль для оценки продуктивности горизонта и определения коэффициента извлечения нефти. Предложен экспресс-метод оценки нефтевытесняющей способности ПАВ, являющийся более экономичным и менее энергозатратным по сравнению со стандартными фильтрационными исследованиями. По результатам проведения фильтрационных испытаний на керне установлено, что предлагаемый метод сопоставим с проведенными исследованиями. В целом предложенная методология выбора ПАВ возможна для внедрения в локальные нормативные документы предприятия-недропользователя и использования с целью подбора необходимого реагента для увеличения нефтеизвлечения. 


\section{СПИСОК ЛИТЕРАТУРЫ}

1. Байков Н.М. Зарубежный опыт внедрения методов увеличения нефтеотдачи // Нефтяное хозяйство. - 2008. - № 12. - С. 101-103.

2. Прочухан К.Ю. Современные методы увеличения нефтеотдачи. Практический опыт применения отечественной технологии Щелочь-ПАВ-Полимер (ASP) на нефтяных месторождениях Западной Сибири // Нефть. Газ. Новации. - 2014. - № 10. - С. 50-54.

3. Hoffman B.T., Kovscek A.R Efficiency and oil recovery mechanisms of steam injection into low permeability, hydraulically fractured reservoirs // Petroleum Science and Technology. - 2004. - V. 22. - № 5-6. - P. 537-564.

4. Муслимов Р.Х. Методы повышения эффективности разработки нефтяных месторождений на поздней стадии // Нефтяное хозяйство. - 2008. - № 3. - С. 30-34.

5. Жданов С.А. Повышение нефтеотдачи пластов на поздней стадии разработки месторождений // Вестник Российской академии естественных наук. - 2017. - Т. 17. - № 5. - С. 8-10.

6. Ibragimov Kh.M., Abdullayeva F., Guseynova N.I. Experience of microbia enhanced oil recovery methods at Azerbaijan fields // Petroleum Science and Technology. - 2017. - V. 35. - № 18. - P. 1822-1830.

7. Фомкин А.В., Жданов С.А. Тенденции применения технологий повышения эффективности нефтеизвлечения // Технологии нефти и газа. -2015 . - № 5. - С. 31-35.

8. Крянев Д.Ю., Жданов С.А. Применение методов увеличения нефтеотдачи пластов в России и за рубежом. Опыт и перспективы // Бурение и нефть. - 2011. - № 2. - С. 22-26.

9. Муслимов Р.Х. Повышение роли методов увеличения нефтеотдачи в обеспечении воспроизводства запасов нефти // Георесурсы. - 2007. - № 3 (22). - С. 2-7.

10. Фомкин А.В., Жданов С.А. Анализ условий для внедрения методов увеличения нефтеотдачи в России и за рубежом // Недропользование XXI век. - 2015. - № 7. - С. 96-105.

11. Перспективы повышения нефтеотдачи карбонатных коллекторов с использованием третичных методов на месторождениях АО «Зарубежнефть» / А.В.Соловьев, М.М.Хайруллин, А.В.Жиров, И.С.Афанасьев, Г.Д. Федорченко // Нефтяное хозяйство. - 2018. - № 9. - C. 48-51.

12. Yin D.D., Li Y.Q., Zhao D.F. Utilization of produced gas of $\mathrm{CO} 2$ flooding to improve oil recovery // Journal of the Energy Institute. - 2014. - V. 84. - № 4. - P. 289-296.

13. Вязкоупругие водные растворы цвиттер-ионных поверхностноактивных веществ для увеличения нефтеотдачи пластов / Р.А. Расулов, А.А.М. Аль-мунтасер, Р.Р. Мингазов, Н.Ю. Башкирцева, Л.Ш. Сибгатуллина // Вестник Казанского технологического университета. - 2015. - Т. 18. - № 9. - С. 85-88.

14. Surfactant and surfactant-polymer flooding for enhanced oil recovery / Abhijit Samanta, Keka Ojha, Ashis Sarkar, Ajay Mandal // Advances in Petroleum Exploration and Development. 2011. - V. 2. - № 1. - P. 13-18.

15. An overview of chemical enhanced oil recovery: recent advances and prospects / A.O. Gbadamosi, R. Junin, M.A. Manan, A. Agi, A.S. Yusuff // International Nano Letters. - 2019. - V. 9. - P. 171-202.

16. Методические особенности проведения экспериментальных исследований по вытеснению нефти газовым и водогазовым воздействием / А.М. Петраков, Ю.А. Егоров, И.А.Лебедев, Т.Л. Ненартович, В.А. Старковский // Нефтяное хозяйство. 2016. - № 2. - C. 60-64.
17. Experimental study of use of ionic liquids in enhanced oil recovery / M.S. Bin-Dahbag, A.A. Al-Qurishi, M.S. Benzagouta, M.M. Kinawy, I.M. Al-Nashif, I. Al-Mushigeh // Journal of Petroleum and Environment Biotechnology. - 2014. - V. 4. - № 6. - P. 1-7.

18. Wormlike micellar solutions, beyond the chemical enhanced oil recovery restrictions / Emad Jafari Nodoushan, Taeil Yi, Young Ju Lee, Namwon Kim // Fluids. - 2019. - V. 4. - № 173. - P. 1-24.

19. A new chemical-enhanced oil recovery method? / S.M. Hosseini-Nasab, P.L.J. Zitha, S.A. Mirhaj, M. Simjoo // Colloids and Surfaces A: Physicochemical and Engineering Aspects. - 2016. - V. 507. - P. 89-95.

20. Исследование свойств низкоконцентрированных растворов ПАВ и композиций на их основе для вытеснения остаточной нефти / Л.С. Бриллиант, Н.Р. Старкова, А.О. Гордеев, В.Г. Новожилов // Нефтяное хозяйство. - 2000. - № 9. - С. 35-38.

21. Muhammad Shahzad Kamal, Syed M. Shakil Hussain, Lionel Talley Fogang. A zwitterionic surfactant bearing unsaturated tail for enhanced oil recovery in high-temperature high-salinity reservoirs // Colloids and Surfaces A: Physicochemical and Engineering Aspects. - 2018. - V. 21. - № 1. - P. 165-174.

22. Муслимов Р.X. Освоение супергигантского Ромашкинского месторождения - выдающийся вклад ученых и специалистов России в мировую нефтяную науку и практику разработки нефтяных месторождений // Георесурсы. - 2008. - № 4 (27). - С. 2-5.

23. Шарипова Н.Д., Севастьянов А.А. Анализ зарубежного и российского опыта по применению ASP-технологии // Электронный периодический научный журнал Sci-article.ru. 2016. - № 33. - С. 119-124.

24. Применение коллоидных систем для увеличения нефтеотдачи пласта / О.Ю. Сладовская, Н.Ю. Башкирцева, Д.А. Куряшов, А.И. Лахова, Р.Р. Мингазов, И.Ф. Исмагилов, Б.Р. Вагапов // Вестник Казанского технологического университета. - 2010. № 10. - C. 585-91.

25. Quality assurance and quality control of surfactants for field-scale enhanced-oil-recovery pilot projects / J.R. Barnes, D.W. Batenburg, M.J. Faber, C.H. Rijn, S. Geib, S.V. Kuijk, D.P. Regalado, T. King, M.J. Doll, L.E. Crom // SPE Reservoir Evaluation \& Engineering. - 2019. - V. 22. - № 2. - P. 565-576.

26. Сравнительная характеристика нефтеотмывающей способности анионных поверхностно-активных веществ отечественного и зарубежного производства / А.В. Ващенко, И.Р. Мукминова, К.Ю. Прочухан, Ю.А. Прочухан // Нефтепромысловое дело. - 2015. - № 8. - С. 44-46.

27. Экспресс-метод исследования пластовых нефтей / К.Д. Ашмян, С.Г. Вольпин, А.К. Пономарев, О.В.Ковалева // Нефтяное хозяйство. - 2016. - № 10. - С. 95-97.

28. Мартюшев Д.А. Лабораторные исследования кислотных составов для обработки коллекторов, характеризующихся различной карбонатностью и структурой пустотного пространства горных пород // Известия Томского политехнического университета. Инжиниринг георесурсов. - 2018. - Т. 329. № 4. - С. 6-12.

29. Сюзев А.В., Лекомцев А.В., Мартюшев Д.А. Комплексная методика подбора реагентов для удаления асфальтеносмолопарафиновых отложений в механизированных нефтедобывающих скважинах // Известия Томского политехнического университета. Инжиниринг георесурсов. - 2018. - Т. 329. № 1. - C. 15-24.

Информация об авторах

Наговицына Н.П., инженер ЗАО «Ижевский нефтяной научный центр».

Дерендяев Р.А., инженер ООО «ЛУКОЙЛ-ПЕРМЬ». 
UDC 622.276

\title{
FORMATION OF A METHODOLOGICAL APPROACH FOR RESEARCH OF SURFACE-ACTIVE SUBSTANCES TO ENHANCED OIL RECOVERY (ON THE EXAMPLE OF DEPOSIT OF THE UDMURT REPUBLIC)
}

\author{
Natalya P. Nagovitsyna ${ }^{1}$, \\ 19nagov97@mail.ru \\ Roman A. Derendyaev², \\ omgvood19@gmail.com \\ 1 CJSC «lzhevsk Oil Research Center», \\ 175, Svobody avenue, Izhevsk, 426057, Russia. \\ 2 LLC «LUKOIL-Perm», \\ 62, Lenin street, Perm, 614990, Russia.
}

\begin{abstract}
The relevance of the research. Currently, most of oil fields of Russia have entered the late stage of development. As there is the depletion of easily recoverable oil reserves, more and more efforts are directed at creating technologies and development methods that allow producing hydrocarbons in difficult conditions. For further development of fields with hard-to-recover reserves, the introduction of new methods for increasing oil recovery and the use of new reagents are required. A significant role in this matter is given to chemical methods, in particular the use of solutions of surfactants. Exposure of aqueous surfactant solutions improves the rheological and filtration characteristics of oil by reducing interfacial tension and increasing wetting ability. In this relation, the task of choosing a surfactant for use in the waterflooding system of reservoirs, as well as the development of methodological approaches for their selection, is of current interest. The main aim of the research is to form a methodological approach to study the surfactants used in the waterflooding system to increase oil recovery.

Object: carbonate collectors of Udmurt Republic.

Methods: laboratory studies of compositions, device for determining the surface tension of surfactant solutions - stalagmometer "Rubin$02 \mathrm{~A}$ ", filtration units with simulation of formation conditions of UIP-5VG and AFS-300, centrifuge process.

Results. The paper identifies the urgent problem - the process of selecting surfactant technology for effective application in the waterflooding system for achieving the highest oil recovery. The surface-active substances that have found active industrial use in the fields of Russia and beyond are analyzed. The physicochemical and technological properties of Russian-made surfactants were evaluated in accordance with the passport characteristics, the requirements of the Provisions of a subsurface user enterprise, and the suitability of chemicals for further use was determined. The paper considers the methodology and results of determining the coefficient of oil displacement with aqueous surfactant solution on core samples taken from deposits in the Udmurt Republic. An express method for assessing the oil-displacing ability of a surfactant is proposed. It is more economical and energy-efficient in comparison with standard filtration studies. According to the results of filtration tests on the core, it was found that the proposed method is comparable with the studies. In general, the proposed methodology for the choice of surfactant composition is possible for implementation in local regulatory documents of a subsoil user enterprise and for use in order to select the necessary reagent to increase oil recovery.
\end{abstract}

\section{Key words:}

Enhanced oil recovery, surface-active substance, coefficient of oil recovery, oil-sweeping ability, physical-chemical properties of SAS, surface tension, displacing properties, oil displacement, carbonate reservoir, critical concentration for micelle formation.

\section{REFERENCES}

1. Baykov N.M. Foreign experience in introducing enhanced oil recovery methods. Oil Industry, 2008, no. 12, pp. 101-103. In Rus.

2. Prochuhan K.Yu. Modern methods of increasing oil recovery. Practical experience of using domestic technology alkalinesurfactant-polymer (ASP) in oil fields of Western Siberia. Oil. Gas. Novation, 2014, no. 10, pp. 50-54. In Rus.

3. Hoffman B.T., Kovscek A.R. Efficiency and oil recovery mechanisms of steam injection into low permeability, hydraulically fractured reservoirs. Petroleum Science and Technology, 2004, vol. 22, no. 5-6, pp. 537-564.

4. Muslimov R.Kh. Methods for increasing the efficiency of oil field development at a late stage. Oil Industry, 2008, no. 3, pp. 30-34. In Rus.

5. Zhdanov S.A. Enhanced oil recovery at a late stage of field development. Bulletin of the Russian Academy of Natural Sciences, 2017, vol. 17, no. 5, pp. 8-10. In Rus.

6. Ibragimov Kh.M., Abdullayeva F., Guseynova N.I. Experience of microbial enhanced oil recovery methods at Azerbaijan fields. Petroleum Science and Technology, 2017, vol. 35, no. 18, pp. $1822-1830$.
7. Fomkin A.V., Zhdanov S.A. Trends in the application of technologies for increasing oil recovery efficiency. Oil and Gas Technologies, 2015, no. 5, pp. 31-35. In Rus.

8. Kryanev D.Yu., Zhdanov S.A. Application of enhanced oil recovery methods in Russia and abroad. Experience and prospects. Drilling and oil, 2011, no. 2, pp. 22-26. In Rus.

9. Muslimov R.Kh. Enhancing the role of enhanced oil recovery methods in ensuring the reproduction of oil reserves. Georesources, 2007, no. 3 (22), pp. 2-7. In Rus.

10. Fomkin A.V., Zhdanov S.A. Analysis of conditions for the introduction of enhanced oil recovery methods in Russia and abroad. Subsoil use XXI century, 2015, no. 7, pp. 96-105. In Rus.

11. Solovyev A.V., Khayrullin M.M., Zhirov A.V., Afanasyev I.S., Fedorchenko G.D. Prospects for enhanced oil recovery of carbonate reservoirs using tertiary methods in the fields of JSC Zarubezhneft. Oil Industry, 2018, no. 9, pp. 48-51. In Rus.

12. Yin D.D., Li Y.Q., Zhao D.F. Utilization of produced gas of $\mathrm{CO}_{2}$ flooding to improve oil recovery. Journal of the Energy Institute, 2014, vol. 84, no. 4, pp. 289-296.

13. Rasulov R.A., Al-muntaser A.A.M., Mingazov R.R., Bashkirceva N.Yu., Sibgatullina L.Sh. Viscoelastic aqueous solutions of zwitterionic 
surfactants to increase oil recovery. Bulletin of Kazan Technological University, 2015, vol. 18, no. 9, pp. 85-88. In Rus.

14. Abhijit Samanta, Keka Ojha, Ashis Sarkar, Ajay Mandal. Surfactant and Surfactant-Polymer Flooding for Enhanced Oil Recovery. Advances in Petroleum Exploration and Development, 2011, vol. 2, no. 1, pp. 13-18.

15. Gbadamosi A.O., Junin R., Manan M.A., Agi A., Yusuff A.S. An overview of chemical enhanced oil recovery: recent advances and prospects. International Nano Letters, 2019, vol. 9, pp. 171-202.

16. Petrakov A.M., Egorov Yu.A., Lebedev I.A., Nenartovich T.L., Starkovskiy V.A. Methodological features of experimental studies on the displacement of oil by gas and water-gas exposure. Oil Industry, 2016, no. 2, pp. 60-64. In Rus.

17. Bin-Dahbag M.S., Al-Qurishi A.A., Benzagouta M.S. Kinawy M.M., Al-Nashif I.M., Al-Mushigeh I. Experimental study of use of ionic liquids in enhanced oil recovery. Journal of Petroleum and Environment Biotechnology, 2014, vol. 4, no. 6, pp. 1-7.

18. Emad Jafari Nodoushan, Taeil Yi, Young Ju Lee, Namwon Kim. Wormlike micellar solutions, beyond the chemical enhanced oil recovery restrictions. Fluids, 2019, vol. 4, no. 173, pp. 1-24.

19. Hosseini-Nasab S.M., Zitha P.L.J., Mirhaj S.A., Simjoo M. A new chemical-enhanced oil recovery method? Colloids and Surfaces A: Physicochemical and Engineering Aspects, 2016, vol. 507, pp. 89-95.

20. Brilliant L.S., Starkova N.R., Gordeev A.O., Novozhilov V.G. Investigation of the properties of low-concentration surfactant solutions and compositions based on them for the displacement of residual oil. Oil Industry, 2000, no. 9, pp. 35-38. In Rus.

21. Kamal M.S., Shakil Hussain S.M., Fogang L.T. A zwitterionic surfactant bearing unsaturated tail for enhanced oil recovery in high-temperature high-salinity reservoirs. Colloids and Surfaces A Physicochemical and Engineering Aspects, 2018, vol. 21, no. 1, pp. $165-174$.

22. Muslimov R.Kh. Development of the Romashkino supergiant field is a great contribution of Russian scientists and experts to world petroleum science and oil development practice. Georesources, 2008, no. 4 (27), pp. 2-5. In Rus.

23. Sharipova N.D., Sevastyanov A.A. Analysis of foreign and Russian experience in the application of ASP-technology. Electronic Periodic Scientific Journal Sci-article.ru, 2016, no. 33, pp. 119-124. In Rus.

24. Sladovskaya O.Yu., Bashkirtseva N.Yu., Kuryashov D.A., Lakhova A.I., Mingazov R.R., Ismagilov I.F., Vagapov B.R. The use of colloidal systems to increase oil recovery. Bulletin of Kazan Technological University, 2010, no. 10, pp. 585-591. In Rus.

25. Barnes J.R., Batenburg D.W., Faber M.J., Rijn C.H., Geib S., Kuijk S.V., Regalado D.P., King T., Doll M.J., Crom L.E. Quality assurance and quality control of surfactants for field-scale enhanced-oil-recovery pilot projects. SPE Reservoir Evaluation \& Engineering, 2019, vol. 22, no. 2, pp. 565-576.

26. Vashchenko A.V., Mukminova I.R., Prochukhan K.Yu., Prochukhan Yu.A. Comparative characteristics of the oil washing ability of anionic surfactants of domestic and foreign production. Oilfield engineering, 2015, no. 8, pp. 44-46. In Rus.

27. Ashmyan K.D., Volpin S.G., Ponomarev A.K., Kovaleva O.V. Express method for the study of reservoir oils. Oil Industry, 2016, no. 10 , pp. 95-97. In Rus.

28. Martyushev D.A. Laboratory research of acid compositions for treating reservoirs characterized by different carbonate content and structure of the void space of rocks. Bulletin of the Tomsk Polytechnic University. Geo Assets Engineering, 2018, vol. 329, no. 4, pp. 6-12. In Rus.

29. Syuzev A.V., Lekomtsev A.V., Martyushev D.A. Complex method for the selection of reagents for the removal of asphalteneresin-paraffin deposits in mechanized oil production wells. Bulletin of the Tomsk Polytechnic University. Geo Assets Engineering, 2018, vol. 329, no. 1, pp. 15-24. In Rus.

Received: 16 June 2020

Information about the authors

Natalya P. Nagovitsyna, engineer, CJSC «Izhevsk Oil Research Center».

Roman A. Derendyaev, engineer, LLC «LUKOIL-Perm». 